\title{
In Vivo Visualization and Quantification of (Disturbed) Oatp-Mediated Hepatic Uptake and Mrp2-Mediated Biliary Excretion of ${ }^{99 m}$ Tc-Mebrofenin in Mice
}

\author{
Sara Neyt*1, Maarten T. Huisman*2, Christian Vanhove ${ }^{3}$, Hilde De Man $^{2}$, Maarten Vliegen², Lieselotte Moerman ${ }^{1}$, \\ Caroline Dumolyn ${ }^{1}$, Geert Mannens ${ }^{2}$, and Filip De $\operatorname{Vos}^{1}$ \\ ${ }^{1}$ Laboratory of Radiopharmacy, Ghent University, Ghent, Belgium; ${ }^{2}$ Drug Safety Sciences, Janssen Research and Development, \\ Janssen Pharmaceutica N.V., Beerse, Belgium; and ${ }^{3}$ IBITech-MEDISIP-INFINITY, Ghent University, Ghent, Belgium
}

\begin{abstract}
Hepatic transport of $99 \mathrm{~m} T \mathrm{~T}-$ mebrofenin through organic anion transport protein $1 \mathrm{a}$ and $1 \mathrm{~b}(\mathrm{Oatp} 1 \mathrm{a} / 1 \mathrm{~b})$ and multidrug resistance protein 2 (Mrp2) was investigated by small-animal SPECT. On the basis of the results, a noninvasive method to visualize and quantify disturbances in hepatic transport is proposed. Methods: Friend virus B wild-type mice (untreated, bile ductligated, vehicle- or rifampicin-treated) and strain-matched knockout mice unable to express the uptake transporters Oatp1a/1b $\left(S / c o 1 a / 1 b^{-1-} /^{-1-}\right)$ or the efflux transporter Mrp2 $\left(A b c c 2^{-/-}\right)$

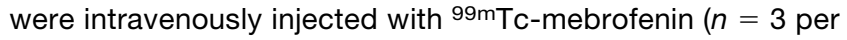
group). After dynamic small-animal SPECT and short CT acquisitions, time-activity curves of the liver and of the gallbladder and intestines were obtained and correlated with direct blood samples. Results: Normal hepatobiliary clearance of $99 \mathrm{mTc}-$ mebrofenin was severely impaired in the bile duct-ligated animal, as evidenced by elevated hepatic tracer levels. In S/co1a/

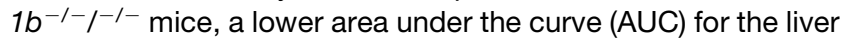
$(P=0.014)$ was obtained and no activity was detected in the gallbladder and intestines. Renal rerouting was observed, along with an increase in the blood AUC $(P=0.01)$. $A b c c 2^{-1-}$ mice had a higher liver AUC $(P=0.009)$, a delayed emergence time of ${ }^{99 m}$ Tc-mebrofenin in the gallbladder $(P=0.009)$, and a lower AUC for the gallbladder and intestines $(P=0.001)$. The blood curve was similar to that of wild-type mice. ${ }^{99 m T c-m e b r o f e n i n}$ disposition was altered after rifampicin treatments. We observed a dose-dependent delayed time point at which tracer maximized in liver, an increased AUC for liver, and a lower AUC for gallbladder and intestines $(P=0.042,0.034$, and 0.001 , respectively, highest dose). Emergence in the gallbladder occurred later $(P=0.009$, highest dose $)$, and blood AUC was higher $(P=0.006)$. Conclusion: The current study visualized and quantified hepatic uptake and biliary efflux of $99 \mathrm{mTc}$-mebrofenin. Our results demonstrated the possibility of discriminating, on a quantitative level, between lack of functional activity of sinusoidal uptake versus that of biliary efflux transporters.
\end{abstract}

Received May 7, 2012; revision accepted Oct. 18, 2012.

For correspondence or reprints contact: Sara Neyt, Laboratory of Radiopharmacy, Harelbekestraat 72, B-9000 Gent, Belgium.

E-mail: sara.neyt@ugent.be

${ }^{*}$ Contributed equally to this work.

Published online Feb. 25, 2013.

COPYRIGHT @ 2013 by the Society of Nuclear Medicine and Molecular Imaging, Inc.
Key Words: ${ }^{99 m}$ Tc-mebrofenin; hepatobiliary transport; smallanimal SPECT; Mrp2; Oatp1a/1b

J Nucl Med 2013; 54:624-630

DOI: 10.2967/jnumed.112.108233

$\mathbf{M}$ ebrofenin labeled with ${ }^{99} \mathrm{~m} \mathrm{Tc}$ is a second-generation hepatic iminodiacetic acid derivative commonly used in nuclear medicine to investigate hepatic function and dysfunction by SPECT (1-4). After intravenous injection, this ionic tracer binds to plasma proteins (3). In the sinusoids of the liver, it is taken up by hepatocytes through a carriermediated, sodium-independent transport mechanism, the organic anion transport protein 1 (OATP1). Mebrofenin is then transported into bile by the active efflux transporter multidrug resistance protein 2 (MRP2) (5), finally entering the small intestine through the common bile duct.

Hepatobiliary transport processes are crucial for the secretion and elimination of toxic compounds (e.g., drugs, carcinogens, and endobiotics) (6,7). Numerous drugs act as both substrates and inhibitors of hepatic transporters such that unexpected and unwanted interactions are frequently observed $(8,9)$, including toxic concentrations of bile acids or substrate drugs in the blood or liver (10). For example, the inhibition of OATPs or MRP2, both of which are transport proteins of mebrofenin, may lead to hyperbilirubinemia $(11,12)$.

In the present study, the hepatobiliary transport of ${ }^{99 \mathrm{~m}} \mathrm{Tc}-$ mebrofenin was investigated in vitro and in vivo. Based on the results, a noninvasive in vivo method is proposed to assess disturbances in the transport of ${ }^{99 \mathrm{~m}} \mathrm{Tc}$-mebrofenin in mice.

Rifampicin mediates the inhibition of OATP1B1 in vitro (13), mouse Oatp1a/1b in vivo (14), and Mrp2 in sandwichcultured rat hepatocytes (15). However, less is known about the effects of rifampicin on the function of hepatic MRP2 in humans, as these may be hard to detect in circulating blood. Thus, rifampicin provided an ideal test compound for this study. We hypothesized that rifampicin inhibits Oatp1a/1b as well as Mrp2, with inhibition reflected in altered time-activity curves for the blood, the liver, and the 
gallbladder and intestines (Fig. 1) (16,17). As a reference, and to investigate in vivo the relative contributions of uptake and efflux transporters in ${ }^{99 \mathrm{~m}} \mathrm{Tc}-$-mebrofenin handling, dynamic small-animal SPECT imaging was used to characterize the behavior of ${ }^{99 \mathrm{~m}} \mathrm{Tc}$-mebrofenin in knockout mice unable to express the uptake transporters Oatp1a/1b (Slcola/l $1 b^{-1-/^{-1-}}$ ) (14) or the efflux transporter Mrp2 $\left(A b c 2^{-/-}\right)(18)$. It was further hypothesized that elevated concentrations of ${ }^{99 \mathrm{~m}} \mathrm{Tc}-$ mebrofenin would be detected in the blood of Slcola/ $1 b^{-1-/^{-1-}}$ mice and in the liver of $A b c c 2^{-\prime-}$ mice (Fig. 1).

Critical for the interpretation and translation of the data in such experiments is a comprehensive mechanistic understanding of the hepatic handling of ${ }^{99 \mathrm{~m}} \mathrm{Tc}$-mebrofenin. ${ }^{99 \mathrm{~m}} \mathrm{Tc}-\mathrm{meb}$ rofenin is an in vitro substrate of OATP1B1, OATP1B3, MRP2, and MRP3 but not of OATP2B1 and natrium taurocholate cotransporting polypeptide (NTCP) $(4,13)$. It is not yet known, as far as we are aware, whether ${ }^{99 \mathrm{~m} T c-}$ mebrofenin (an anion) is a substrate for organic cation transporter 1 (OCT1), although such a possibility is unlikely. Considering the high-level expression of OCT1 in the sinusoidal membrane, in the present work it was also important to formally exclude OCT1-mediated ${ }^{99 \mathrm{~m} T c-m e b r o f e n i n ~ t r a n s p o r t . ~}$

\section{MATERIALS AND METHODS}

\section{In Vitro Assays}

Chinese hamster ovary cells (CHO-K1) were purchased from ATCC and served as controls for the transfected cell lines. CHONTCP and CHO-OATP1B1 cells were purchased from Solvo Biotechnologies; CHO-OCT1 cells were a kind gift from the same company. CHO-NTCP, CHO-OATP1B1, and CHO-OCT1 cells were stably transfected with genes encoding human NTCP (SLC10A1), OATP1B1 (SLCO1B1), and OCT1 (SLC22A1), respectively. The cell lines were cultured in a humidified atmosphere at $37^{\circ} \mathrm{C}$ in the presence of $5 \% \mathrm{CO}_{2}$. The culture medium consisted of Dulbecco modified Eagle's medium (Invitrogen), supplemented with $10 \%$ fetal calf serum, $4 \mathrm{mM}$ L-glutamine, and $1 \mathrm{mM}$ sodium pyruvate, without antibiotics.
For transport experiments, all $\mathrm{CHO}$ cells were seeded in 24 -well plates $\left(6.0 \times 10^{5}\right.$ cells per well $)$ in $1 \mathrm{~mL}$ of culture medium. After 18-24 h, the medium was removed and the cells were washed twice with washing buffer $(1.25 \mathrm{~mL}$ of sterile Hanks balanced salt solution with $\mathrm{Ca}^{2+}$ and $\mathrm{Mg}^{2+}, 10 \mathrm{mM} \mathrm{N}$-(2-hydroxyethyl) piperazine- $N^{\prime}$-(2-ethanesulfonic acid), $1 \%$ bovine serum albumin, $\left.\mathrm{pH} 7.4,37^{\circ} \mathrm{C}\right)$. Incubation buffers $(500 \mu \mathrm{L} /$ well $)$ were obtained by adding the (radiolabeled) compounds to the washing buffer. Final concentrations were $1 \mu \mathrm{M}{ }^{3} \mathrm{H}$-estradiol-17 $\beta$-glucuronide (for OATP1B1), $1 \mu \mathrm{M}{ }^{3} \mathrm{H}$-taurocholic acid (for NTCP), $50 \mu \mathrm{M}$ ${ }^{14} \mathrm{C}$-tetraethyl ammonium (for OCT1), and $0.066 \mathrm{nM}{ }^{99 \mathrm{~m} T \mathrm{~T}-}$ mebrofenin (for all cell lines). The plates were incubated at $37^{\circ} \mathrm{C}$ and $0 \% \mathrm{CO}_{2}$ with shaking. The incubation was stopped by adding $1.5 \mathrm{~mL}$ of ice-cold Hanks balanced salt solution with $\mathrm{Ca}^{2+}$ and $\mathrm{Mg}^{2+}$ (1\% bovine serum albumin), after which the wells, containing the cells, were washed twice more. Next, the cells were lysed with $200 \mu \mathrm{L}$ of mammalian protein extraction reagent and the plates were shaken for $10 \mathrm{~min}$ at $120 \mathrm{rpm}$. A $150-\mu \mathrm{L}$ aliquot of this solution was used for liquid scintillation counting.

\section{Murine Models}

Friend virus B wild-type (WT) mice (female; age, 5 wk; weight, 20-25 g) were from Janvier, and Slcola/1 $1 b^{-1-/^{-1}}$ (male; age, $5 \mathrm{wk}$; weight, 25-30 g) and $A b c c 2^{-/-}$mice (female; age, 5 wk; weight, 20-25 g) were from Taconic Farms. The mice were housed and handled according to guidelines approved by the European Ethics Committee and acclimatized for at least $1 \mathrm{wk}$ before the experiments. All animals were kept under environmentally controlled conditions (12-h normal light/dark cycles, $20^{\circ} \mathrm{C}-22^{\circ} \mathrm{C}$, and $60 \%$ relative humidity) with food and water ad libitum. The study protocol was approved by the Animal Experimental Ethical Committee of Ghent University (ECD10/39).

\section{Radionuclides, Radiopharmaceuticals, and Chemicals}

Mebrofenin ( $N$-(3-bromo-2,4,6 trimethylphenylcarbamoylmethyl)iminodiacetic acid) was obtained as a commercial kit (Bridatec; GE Healthcare) in a preparation containing $40 \mathrm{mg}$ of mebrofenin and $0.3 \mathrm{mg}$ of tin(II)chloride-dihydrate. ${ }^{99} \mathrm{TcO}_{4}{ }^{-}$was eluted from a sterile ${ }^{99 \mathrm{~m}} \mathrm{Tc}$-generator (Drytec; GE Healthcare). The

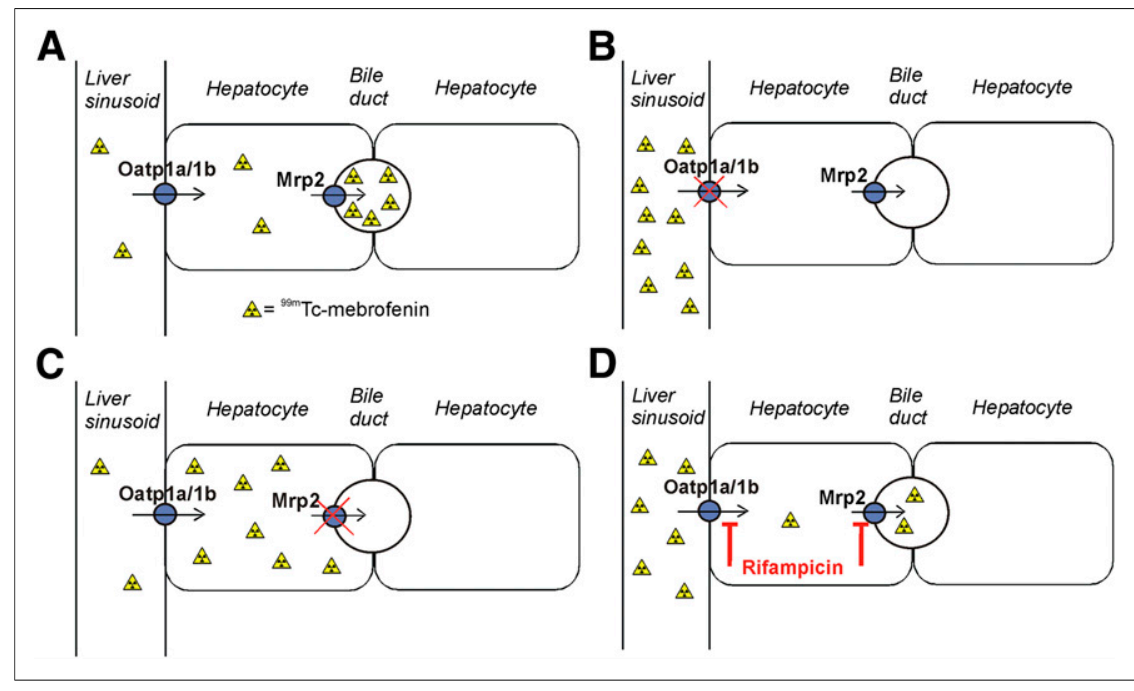

FIGURE 1. Study hypothesis for WT (A), S/co1a/1b $b^{-1-/-/-}$ (deficient in Oatp1a/1b transporters) (B), Abcc2 $2^{-1-}$ (deficient in Mrp2 transporter) (C), and rifampicin-treated (D) mice. In WT mice, rapid uptake in liver and efflux to gallbladder and intestines were expected, in contrast to Slco1a/1 $b^{-/-} /^{-1-}$ mice, in which no noteworthy uptake was anticipated. In $A b c c 2$ $-1-$ mice, normal uptake in liver and absence of efflux to gallbladder and intestines were hypothesized, whereas in rifampicintreated mice, decreased uptake and efflux were assumed. 
Bridatec kit was reconstituted according to the manufacturer's recommendations with $1,480 \mathrm{MBq}$ of ${ }^{99} \mathrm{TcO}_{4}{ }^{-}$in $4 \mathrm{~mL}$ of saline. Radiochemical purity was determined according to the method of Billinghurst et al. (19). The formulations used had a radiochemical purity of at least $95 \%$.

Rifampicin and polyethylene glycol 400 were obtained from Sigma Aldrich, and dimethyl sulfoxide (DMSO) was from Acros Organics.

\section{Molecular Imaging}

The mice were imaged using a small-animal SPECT camera (U-SPECT-II/CT; MiLabs) equipped with a cylindric collimator containing 75 pinholes of $1-\mathrm{mm}$ diameter (rat whole-body collimator; spatial resolution, $0.8 \mathrm{~mm}$ ). All acquisitions were obtained in list mode.

After an overnight fast (minimum, $6 \mathrm{~h}$ ), the mice were anesthetized with isoflurane and $\mathrm{O}_{2}$ to allow placement of intravenous polyethylene tubing (PE10; Becton Dickinson) in a lateral tail vein. One hour before tracer injection, rifampicin-treated mice were pretreated with 5 different rifampicin doses (100, 50, 37.5, 25 , or $12.5 \mathrm{mg} / \mathrm{kg}$ in $100 \mu \mathrm{L}$ of DMSO, intraperitoneally), and the control mice were pretreated with vehicle $(100 \mu \mathrm{L}$ of DMSO, intraperitoneally). During tracer injection, a second dose of rifampicin $(25,12.5,9.37,6.25$, or $3.12 \mathrm{mg} / \mathrm{kg})$ or vehicle was intravenously coadministered.

In one WT animal, ligatures were placed posterior and anterior to the gallbladder to obstruct bile flow completely. Immediately after surgery, the bile duct-ligated mouse was placed supine and all other mice prone on the mouse scanner bed.

The mice were imaged while anesthetized, with their body temperature maintained during imaging using a heated bed. The field of view was chosen on the basis of a 30-s CT acquisition. Subsequently, a 15-min dynamic SPECT acquisition using 60 time frames of $15 \mathrm{~s}$ each was initiated $5 \mathrm{~s}$ before the injection of $200 \mu \mathrm{L}$ of ${ }^{99 \mathrm{~m}} \mathrm{Tc}-$ mebrofenin $(2.7 \mathrm{mg}$ of mebrofenin, $74 \mathrm{MBq})$. Rifampicin-treated and vehicle-control mice were coinjected, respectively, with rifampicin $(25,12.5,9.37,6.25$, or $3.12 \mathrm{mg} / \mathrm{kg})$ and vehicle (100 $\mu \mathrm{L}$ of polyethylene glycol 400:saline, 30:70, v:v). Lastly, a CT acquisition (5 min; tube current, $612 \mu \mathrm{A}$; tube voltage, $50 \mathrm{kV}$ ) was obtained for anatomic correlation.

SPECT acquisitions were iteratively reconstructed using an ordered-subsets expectation maximization algorithm (3 iterations; 16 subsets; 0.75 -mm voxel size; decay correction). Only those photons within an energy range of $140 \pm 20 \mathrm{keV}$ were included from the acquired list-mode data. Finally, 3 regions of interest were manually drawn over the liver, the gallbladder and intestines, and the urinary bladder using PMOD software (PMOD Technologies), with region-of-interest volumes of between 67 and 1,578 $\mathrm{mm}^{3}$. From these dynamic measurements, time-activity curves were obtained.

To assess the linearity of the small-animal SPECT camera, 10 samples with predetermined amounts of ${ }^{99} \mathrm{~m} \mathrm{TcO}_{4}{ }^{-}$ranging from 0.37 to $74 \mathrm{MBq}$ and measured with a $\mathrm{CRC}-15 \mathrm{R}$ dose calibrator (Capintec) were scanned in the same dynamic mode. The resulting calibration curve was used to quantify the amount of radioactivity. The total activity in each organ, expressed in megabecquerels (normalized to an injection of $37 \mathrm{MBq}$ and a mouse weight of $20 \mathrm{~g}$ ), was expressed as a function of time (in seconds).

\section{Determination of ${ }^{99 m}$ Tc-Mebrofenin Blood Curve}

After an overnight fast, the mice were injected with $200 \mu \mathrm{L}$ of ${ }^{99 \mathrm{~m}} \mathrm{Tc}-\mathrm{mebrofenin}(2.7 \mathrm{mg}, 74 \mathrm{MBq})$ through a lateral tail vein.
Blood samples $(30 \mu \mathrm{L})$ were taken by intravenous puncture in the contralateral tail vein at $1,2,5,7,10$, and 15 min after injection. The radioactivity contained in these samples was counted in a calibrated $\mathrm{NaI}(\mathrm{Tl})$ scintillation detector (Perkin Elmer).

To determine the blood curve of rifampicin-treated mice, the animals were pretreated with the drug $(100,50,37.5,25$, or $12.5 \mathrm{mg} / \mathrm{kg}$ in $100 \mu \mathrm{L}$ of DMSO, intraperitoneally) or with vehicle (100 $\mu \mathrm{L}$ of DMSO). Rifampicin $(25,12.5,9.37,6.25$, or $3.12 \mathrm{mg} / \mathrm{kg}$ in $100 \mu \mathrm{L}$ of polyethylene glycol 400:saline, $30: 70, \mathrm{v}: \mathrm{v})$ or vehicle was also coinjected with the tracer. Blood samples were then taken and used to plot the area under the curve (AUC) for blood and the half-time $\left(\mathrm{T}_{1 / 2}\right)$ values of the rapid and slow phases.

\section{Statistical and Kinetic Analysis}

Statistical analysis was performed using Prism, version 3.00 (GraphPad), and SPSS, version 19, for Windows (Microsoft). The time-activity curves were described by calculating the maximal tracer amount $\left(\mathrm{C}_{\max }\right)$ in the liver and in the gallbladder and intestines, the time point at which tracer maximized or plateaued $\left(\mathrm{T}_{\max }\right)$ in the liver, and the AUC in the liver and in the gallbladder and intestines. Additionally, as a measure of Mrp2 transport, the tracer emergence time in the gallbladder was determined, defined as the time point when the activity in the gallbladder appeared in the dynamic SPECT data. AUCs were calculated using the trapezoidal method. To obtain rifampicin dose-response curves, liver $\mathrm{T}_{\text {max }}$ and gallbladder/intestine AUC were expressed as a function of the administered doses. Liver $\mathrm{T}_{\max }$ was a measure of ${ }^{99 \mathrm{~m}} \mathrm{Tc}-$ mebrofenin uptake, and gallbladder/intestine AUC was a measure of ${ }^{99 \mathrm{~m} T c-m e b r o f e n i n}$ efflux. Biexponential curve fitting was applied in generating the blood curves. $\mathrm{T}_{1 / 2}$ values were computed using the method of least squares. Differences between 2 groups were tested for significance using the nonparametric Mann-Whitney test for 2 groups. All experiments were performed on 3 samples (unless stated otherwise); a $P$ value of 0.05 was considered significant.

\section{RESULTS}

\section{In Vitro Assessment of Potential Role of OCT1}

Small-scale in vitro experiments using stably transfected CHO cells and parental controls confirmed the OATP1B1mediated transport of ${ }^{99 m}$ Tc-mebrofenin and a lack of detectable transport by NTCP $(4,15)$. Not unexpectedly, in the transfected cells OCT1-mediated transport could not be demonstrated, whereas ${ }^{14} \mathrm{C}$-tetraethyl ammonium uptake was $21 \pm 6.0$-fold higher than in the parental controls (Fig. 2).

\section{Friend Virus B WT Mice}

Figure 3A depicts the time-activity curves of ${ }^{99 \mathrm{~m}} \mathrm{Tc}-$ mebrofenin in Friend virus B WT mice. The liver $\mathrm{C}_{\max }$ $(19.2 \pm 2.4 \mathrm{MBq})$ was reached after $134 \pm 41 \mathrm{~s}$ (liver $\mathrm{T}_{\max }$ ) and was followed by a rapid exponential decrease to the background level within $15 \mathrm{~min}(900 \mathrm{~s})$, with a $\mathrm{T}_{1 / 2}$ of $148 \pm 27 \mathrm{~s}$. According to the dynamic SPECT data, the mean appearance time of ${ }^{99 \mathrm{~m}} \mathrm{Tc}-$ mebrofenin in the gallbladder was $147 \pm 26 \mathrm{~s}$ (Table 1). At the end of the acquisition, most of ${ }^{99} \mathrm{~m}$ Tc-mebrofenin was found in the intestines. 


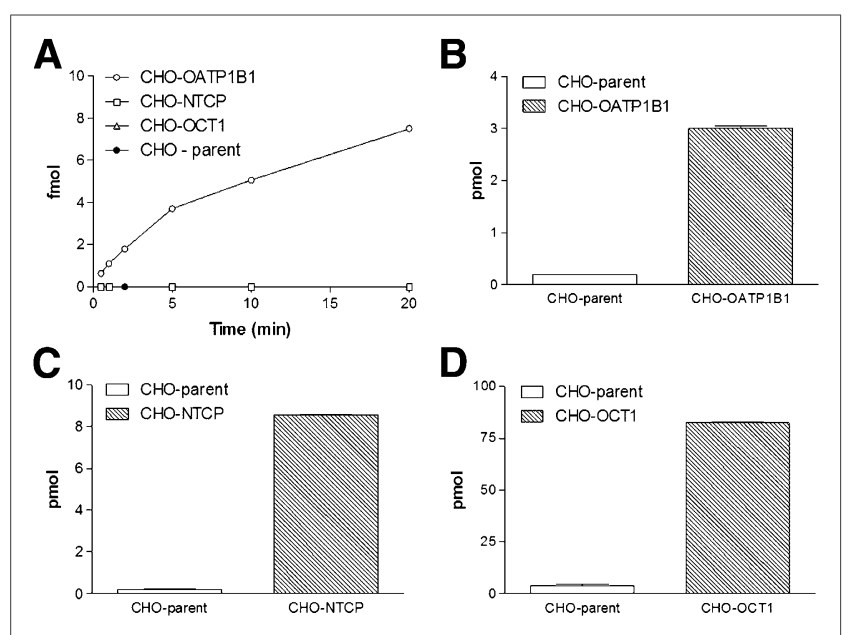

FIGURE 2. (A) ${ }^{99 m}$ Tc-mebrofenin uptake: mebrofenin is transported only through OATP1B1. (B-D) Positive controls: ${ }^{3} \mathrm{H}$-estradiol$17 \beta$-glucuronide uptake (B), ${ }^{3} \mathrm{H}$-taurocholate uptake (C), and ${ }^{14} \mathrm{C}$-tetra-ethyl-ammonium uptake (D).

The venous blood curve was consistent with a 2-compartment model, characterized by an initial rapid decline of the radiopharmaceutical from the blood (fast phase), with a $T_{1 / 2}$ of $17 \pm 2 \mathrm{~s}$, due to its distribution within the vascular space and the high extraction rate of ${ }^{99 \mathrm{~m}} \mathrm{Tc}-\mathrm{mebrofenin}$ by the liver. This initial decline was followed by a slower decline (slow phase) with a $\mathrm{T}_{1 / 2}$ of $332 \pm 121 \mathrm{~s}$, reflecting the lower concentration of 99m Tc-mebrofenin in the blood (Table 1).

\section{Bile Duct Ligature (BDL): Proof of Principle}

Next, we investigated the effect of complete obstructive cholestasis, induced by BDL in a WT animal, on mebrofenin transport. In mice that did not undergo BDL, typical time-activity curves were obtained in the blood, the liver, and the gallbladder and intestines.
The effect of BDL, that is, obstructive cholestasis and thus a higher concentration of ${ }^{99 \mathrm{~m}} \mathrm{Tc}-$ mebrofenin in the liver, is clearly seen by comparing Figure 3A with Figure 3B. Although in the time-activity curve of WT mice a peak in the liver was followed by a rapid decrease to background levels, in the time-activity curve of the BDL animal there was a continuous increase of ${ }^{99 \mathrm{~m}} \mathrm{Tc}-\mathrm{mebrofenin}$ uptake in the liver, with a maximum of $28.39 \mathrm{MBq}$. The tracer was not subsequently cleared but instead remained in the liver for up to $900 \mathrm{~s}$ after injection. Expressed as liver AUC (MBq.s), the activity was 3.5-fold higher in the liver of the BDL animal than in nontreated animals (non-BDL and BDL: 6,417 MBq.s and 22,202 MBq.s, respectively). The gallbladder/intestine AUC was 17,808 MBq.s in the nontreated animal and undetectable in the BDL animal. Taken together, the total activity in the liver and in the gallbladder and intestines was nearly identical in the 2 treatment groups (non-BDL, 24,225 MBq-s, vs. BDL, 22,202 MBq.s).

\section{Role of Oatp1a/1b Transporters in Hepatic Transport of ${ }^{99 m}$ Tc-Mebrofenin}

Subsequently, the relative role of the uptake transporter family Slc01a/lb on the hepatic handling of ${ }^{99 \mathrm{~m} T c-m e b r o-}$ fenin was determined. The time-activity curves of the Slc01a/1 $b^{-1-} /^{-1-}$ animals are shown in Figure 3C.

Most of ${ }^{99} \mathrm{~m} \mathrm{Tc}-m e b r o f e n i n$ activity was located in the blood and urinary bladder, with only a small amount of activity detected in the liver. ${ }^{99 \mathrm{~m}} \mathrm{Tc}-$ mebrofenin levels in the gallbladder and intestines did not exceed the limit of quantification. This was in contrast to the WT mice, in which most of the ${ }^{99 \mathrm{~m}} \mathrm{Tc}-\mathrm{mebrofenin}$ was found in the gallbladder and intestines.

Specifically, the mean time-activity curve for the liver in Slcola/lb knockout mice did not exceed baseline levels. The liver AUC was 3.4-fold lower in Slcola/lb knockout mice than in WT animals $(P=0.014)$ (Table 1$)$. At the final

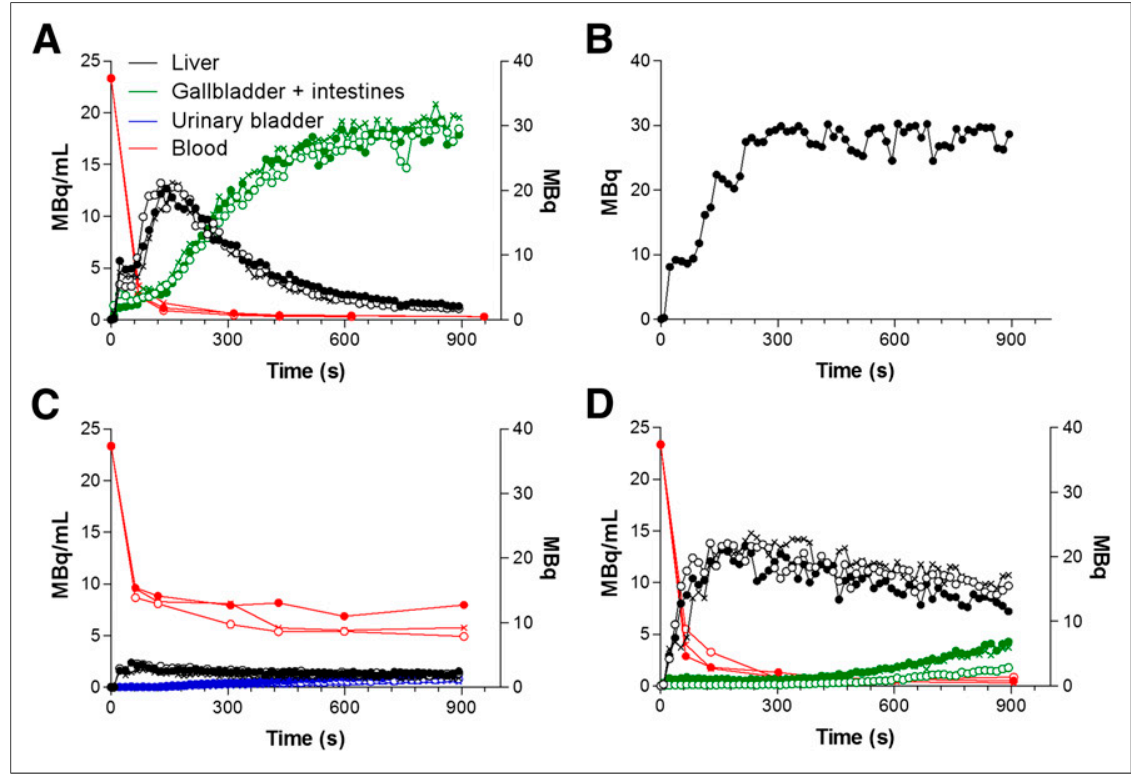

FIGURE 3. Time-activity and blood curves in 3 WT mice (A), 1 bile duct-ligated mouse (B), 3 Slco1a/1 $b^{-1-} /^{-1-}$ (deficient in Oatp 1a/1b transporters) mice (C), and 3 Abcc2 ${ }^{-1-}$ (deficient in Mrp2 transporter) knockout mice (D). Time-activity curves for liver, for gallbladder and intestine, and for urinary bladder are expressed in megabecquerels. Blood curves are expressed in $\mathrm{mBq} / \mathrm{mL}$. $=$ mouse $1 ; \bigcirc=$ mouse $2 ; \times=$ mouse 3 . 


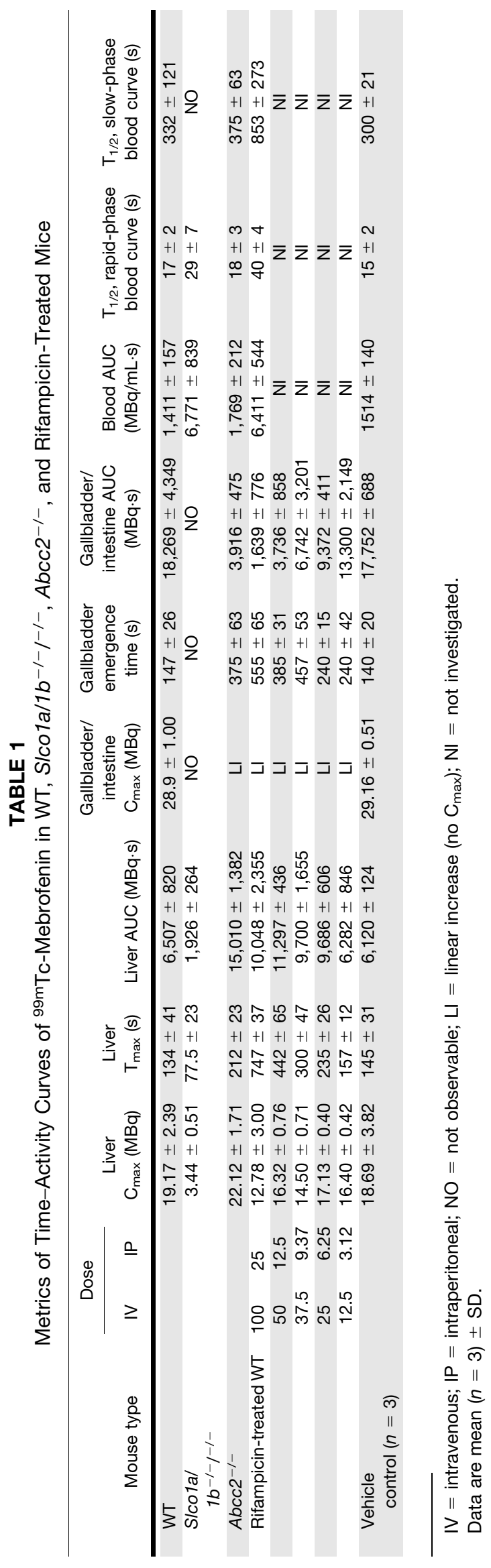

time point, $4.1 \%$ of the injected dose was present in the urinary bladder. In the blood, the mean AUC was 5.1-fold larger in the Slcola/lb knockout mice than in their WT counterparts $(P=0.01)$ (Fig. 3C; Table 1).

\section{Role of Mrp2 Transporter in Hepatic Transport of ${ }^{99 m}$ Tc-Mebrofenin}

The distribution of ${ }^{99 \mathrm{~m}} \mathrm{Tc}-\mathrm{mebrofenin}$ to the livers of Abcc2-deficient mice was similar to that observed in WT mice (Fig. 2D; Table 1). This observation was supported by similar $\mathrm{C}_{\max }(P=0.15)$ values between the 2 genotypes. Overall, the liver AUC of $A b c c 2$ knockout mice was 2.3 -fold higher than that of WT mice $(P=0.009)$ (Table 1$)$, mainly because of the impaired hepatic clearance (Fig. 2D). In line with the observations from WT animals, the activity in the urinary bladder was too low to be quantified.

As shown in Table 1, activity in the gallbladder was observed after $375 \pm 63 \mathrm{~s}$ in Abcc2-deficient animals, compared with $147 \pm 26 \mathrm{~s}$ in their WT counterparts $(P=0.009)$. The gallbladder/intestine AUC was 4.7-fold lower in the $A b c c 2$-deficient mice than in the WT mice $(P=0.001)$.

The blood curve (Fig. 2D) and corresponding metrics (Table 1) of the $A b c c 2^{-1-}$ mice were comparable to those of the WT mice ( $P$ values for the rapid phase, slow phase, clearance, and AUC were $0.65,0.88,0.07$ and 0.06 , respectively).

\section{Effect of Different Rifampicin Doses on Hepatic Transport of ${ }^{99 m}$ Tc-Mebrofenin}

The data generated thus far allowed us to investigate mechanistically the role of uptake and efflux transporters in the in vivo disposition of ${ }^{99 \mathrm{~m}} \mathrm{Tc}-m e b r o f e n i n$. With this framework established, we aimed to determine whether it was possible to discriminate dose-dependently between the inhibition of hepatic uptake transporters and that of efflux transporters. Because rifampicin is both a substrate and an inhibitor of OATPs and MRP2, it was selected as the test agent.

The time-activity curves of the vehicle-control and rifampicin-treated (highest dose, $100 \mathrm{mg} / \mathrm{kg}$ intraperitoneally, $25 \mathrm{mg} / \mathrm{kg}$ intravenously) mice are shown in Figure 4. The time-activity curves in the control mice were similar to those in the untreated WT mice. The metrics of the different rifampicin doses are shown in Table 1.

The liver $\mathrm{T}_{\max }$ was 5.1-fold higher in mice treated with the highest dose of rifampicin than in vehicle-control mice $(P=0.042)$, whereas the liver AUC was 1.6-fold higher $(P=$ $0.034)$. Moreover, the mean emergence time of tracer activity in the gallbladder was prolonged 4.0 -fold in rifampicintreated mice $(P=0.025)$ whereas the gallbladder/intestine AUC decreased by a factor of $10(P=0.001)$. A urinary bladder time-activity curve could be determined in the rifampicin-treated mice but not in the vehicle-control mice.

The mean blood AUC in mice treated with the highest dose of rifampicin was 4.3 -fold greater than that in their vehicle-control counterparts $(P=0.006)$. Additionally, $\mathrm{T}_{1 / 2}$ values were 2.8 -fold higher $(P=0.032$ and $P=0.034$ for the rapid and slow phases, respectively). 


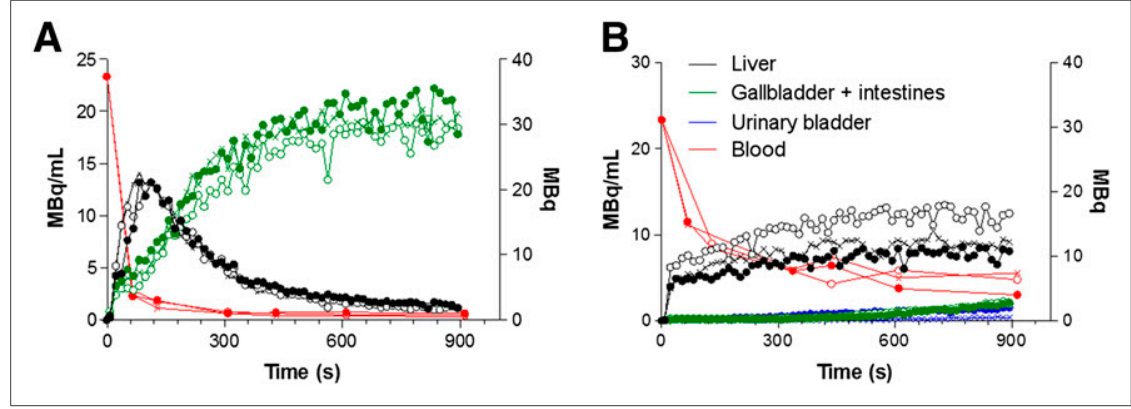

FIGURE 4. Time-activity and blood curves in 3 vehicle-control mice $(A)$ and in 3 rifampicin-treated mice (B). Time-activity curves for liver, for gallbladder and intestine, and for urinary bladder are expressed in megabecquerels. Blood curves are expressed in $\mathrm{MBq} / \mathrm{mL}$. $=$ mouse $1 ; \bigcirc=$ mouse 2 ; $x=$ mouse 3 .
The rifampicin dose-response curves evidenced the effect of the drug on ${ }^{99 \mathrm{~m}} \mathrm{Tc}-\mathrm{mebrofenin}$ uptake and efflux, with higher doses leading to a delayed liver $\mathrm{T}_{\max }$ and to a lower gallbladder/intestine AUC (Table 1; Supplemental Fig. 1 [supplemental materials are available online only at http://jnm.snmjournals.org]).

\section{DISCUSSION}

Drug-induced liver injury is one of the leading causes for the withdrawal of approved drugs from the market (9), highlighting the importance of assessing this effect early on in drug research. One of the underlying causes of drug-induced liver injury is an altered functional activity of hepatic uptake or efflux transporters. In this study, we investigated ${ }^{99 \mathrm{~m}} \mathrm{Tc}-$ mebrofenin transport through Oatp and Mrp2. On the basis of the results, we were able to propose a noninvasive method to visualize and quantify altered hepatobiliary transporter activity. Moreover, the proposed method enables differentiation between altered influx and efflux. By using dynamic SPECT measurements to calculate time-activity curves that quantify transport via the liver to the gallbladder and intestines, our method offers a novel approach, as thus far it has not been possible either to visualize or quantify in vivo hepatic drug interactions and the differentiation between uptake and efflux alterations.

Mice express 8 Oatp1a/1b transporters whereas humans express only 3 OATP transporters (OATP1A/1B1, OATP1A/ 2B1, and OATP1A/1B3). Here, the specificity for mebrofenin was investigated by means of $\mathrm{CHO}$ cell lines expressing these human transporters. Our data confirmed the results of Ghibellini et al. (4). Additionally, the current study was able to exclude OCT1 as a mebrofenin transporter.

The primary aim of our study was the visualization of disturbed hepatobiliary transporter function. As proof of principle, a BDL was placed so as to simulate extrahepatic cholestasis. This mechanical inhibition caused the complete obstruction of bile flow and subsequently the accumulation of ${ }^{99 \mathrm{~m}} \mathrm{Tc}$-mebrofenin in the liver, thus demonstrating the ability of the proposed method to visualize and quantify disturbances in hepatobiliary transport.

To examine the possibility of distinguishing between uptake and efflux transporter alterations, Slcola/lb and $A b c c 2$ knockout mice were investigated. Experiments in the Slcola/lb knockout mice confirmed the critical role played by transporters of the Oatp1a/1b family in the hepatic uptake of ${ }^{99 \mathrm{~m}} \mathrm{Tc}$ mebrofenin, consistent with the findings of van de Steeg et al. (14). The time-activity curves of Slcola/lb knockout mice did not exceed baseline levels, because of the impaired hepatic uptake of mebrofenin. Consequently, blood concentrations were elevated,

We were also able to show that the biliary efflux transporter Mrp2 is involved in ${ }^{99 \mathrm{~m}} \mathrm{Tc}$-mebrofenin transport. Specifically, in $A b c c 2$ knockout mice the absence of the efflux transporter led to the hepatic accumulation of ${ }^{99 \mathrm{~m} T c}$ mebrofenin, reflected in a higher $\mathrm{AUC}_{\text {liver }}$. Consequently, less ${ }^{99 \mathrm{~m}} \mathrm{Tc}$-mebrofenin reached the gallbladder and intestines, resulting in a lower gallbladder/intestine AUC and a delayed tracer emergence time. The corresponding blood concentrations were comparable to those of the WT animals, since hepatic uptake was not disturbed.

To assess the effect of pharmacologic inhibition on transporter activity, rifampicin was administered to WT mice, by both the intraperitoneal and the intravenous routes. This double administration led to the impaired uptake and efflux of ${ }^{99 \mathrm{~m}} \mathrm{Tc}-$-mebrofenin. Inhibition of mebrofenin uptake occurs at the level of the basolateral (sinusoidal) Oatps, with rifampicin acting as a competitive inhibitor of the transporters (20). Because hepatic uptake was impaired, the liver $\mathrm{T}_{\max }$ of mebrofenin was delayed and blood concentrations of the tracer were elevated. Additionally, urinary elimination of ${ }^{99 \mathrm{~m}} \mathrm{Tc}$-mebrofenin was increased in rifampicin-treated mice. This increase in renal excretion reflected the decreased uptake of ${ }^{99 \mathrm{~m}} \mathrm{Tc}-\mathrm{mebrofenin}$ through Oatp1a/1b and the increased blood concentrations (higher blood AUC). Rifampicin is both a substrate and an inhibitor of Oatps. Therefore, a certain amount of rifampicin (dependent on the dose) is able to enter hepatocytes, where it inhibits the Mrp2 transporter at the level of the canalicular membrane. Consequently, an accumulation of mebrofenin in the liver (higher liver AUC) can be detected, whereas the decreased amounts of mebrofenin in the intestines are due to a combination of Oatp and Mrp2 inhibition (lower gallbladder/intestine AUC). These observations suggest that the impaired liver uptake and efflux are caused by a combination of rifampicin-mediated Oatp1a/1b and Mrp2 inhibition $(15,21)$. To the best of our knowledge, Mrp2 inhibition has not been previously shown in vivo. Our study demonstrated the feasibility of visualizing 
and quantifying the effect of Oatp1a/1b and Mrp2 modulation by various drugs in vivo, with rifampicin as a model drug, and confirmed the findings of van de Steeg et al. (14) with methotrexate and tritium-labeled fexofenadine.

Additionally, we were able to show that slight alterations in transporter activity can be detected with the proposed method. From mice administered 5 different rifampicin doses, a dose-response curve of the rifampicin-mediated inhibition of ${ }^{99 \mathrm{~m}} \mathrm{Tc}$-mebrofenin transport was obtained. The data demonstrated a dose-dependent effect on the uptake and efflux of ${ }^{99 \mathrm{~m}} \mathrm{Tc}$-mebrofenin. Higher doses of rifampicin delayed the liver $\mathrm{T}_{\max }$ and caused a smaller gallbladder/ intestine AUC, representing decreases in hepatic uptake and decreases in efflux to the gallbladder and intestines, respectively. Although Mrp2 inhibition occurred at low rifampicin concentrations $(12.5 \mathrm{mg} / \mathrm{kg}$ intraperitoneally, $6.25 \mathrm{mg} / \mathrm{kg}$ intravenously), Oatp inhibition was first seen at higher concentrations of the drug $(37.5 \mathrm{mg} / \mathrm{kg}$ intraperitoneally, $9.37 \mathrm{mg} / \mathrm{kg}$ intravenously).

\section{CONCLUSION}

This study showed that it is possible to discriminate quantitatively between the lack of functional activity of sinusoidal uptake and that of biliary efflux transporters. The method described herein therefore offers a promising approach to investigate the interaction between new chemical entities and hepatobiliary transporters. The current study visualized and quantified hepatic uptake and biliary efflux of ${ }^{99 \mathrm{~m}} \mathrm{Tc}-\mathrm{mebrofenin}$ in WT, Slcola/lb knockout, $A b c c 2$ knockout, and rifampicin-treated mice. The data demonstrated that the transport activities of Oatp $1 \mathrm{a} / 1 \mathrm{~b}$ (hepatic uptake) and Mrp2 (biliary efflux) can be quantified simultaneously in vivo. Moreover, pharmacologic modulation of these activities could be demonstrated in a dose-dependent manner using rifampicin as a model drug.

\section{DISCLOSURE}

The costs of publication of this article were defrayed in part by the payment of page charges. Therefore, and solely to indicate this fact, this article is hereby marked "advertisement" in accordance with 18 USC section 1734. IWT Belgium and the GROUP-ID consortium provided financial support. No other potential conflict of interest relevant to this article was reported.

\section{ACKNOWLEDGMENTS}

We thank Scharon Bruneel for her contributions to the imaging experiments.

\section{REFERENCES}

1. Bujanover Y, Bar-Meir S, Hayman I, Baron J. ${ }^{99 \mathrm{~m} T c-H I D A}$ cholescintigraphy in children with Dubin-Johnson syndrome. J Pediatr Gastroenterol Nutr. 1983;2: 311-312.

2. Newell SM, Graham JP, Roberts GD, et al. Quantitative hepatobiliary scintigraphy in normal cats and in cats with experimental cholangiohepatitis. Vet Radiol Ultrasound. 2001;42:70-76.

3. Morandi F, Frank N, Avenell J, Daniel GB. Quantitative assessment of hepatic function by means of $99 \mathrm{~m}$ Tc-mebrofenin in healthy horses. $J$ Vet Intern Med. 2005;19:751-755.

4. Ghibellini G, Leslie EM, Pollack GM, Brouwer KLR. Use of Tc-99m mebrofenin as a clinical probe to assess altered hepatobiliary transport: integration of in vitro, pharmacokinetic modeling, and simulation studies. Pharm Res. 2008;25: 1851-1860.

5. Nies AT, Keppler D. The apical conjugate efflux pump ABCC2 (MRP2). Pflugers Arch. 2007;453:643-659.

6. Kullak-Ublick GA, Stieger B, Hagenbuch B, Meier PJ. Hepatic transport of bile salts. Semin Liver Dis. 2000;20:273-292.

7. Wolkoff AW, Cohen DE. Bile acid regulation of hepatic physiology: hepatocyte transport of bile acids. Am J Physiol Gastrointest Liver Physiol. 2003;284:G175G179.

8. Shitara Y, Sato H, Sugiyama Y. Evaluation of drug-drug interaction in the hepatobiliary and renal transport of drugs. Annu Rev Pharmacol Toxicol. 2005; 45:689-723.

9. Maddrey WC. Drug-induced hepatotoxicity. J Clin Gastroenterol. 2005;39 (suppl):S83-S89.

10. Padda MS, Sanchez M, Akhtar AJ, Boyer JL. Drug-induced cholestasis. Hepatology. 2011;53:1377-1387.

11. Alrefai WA, Gill RK. Bile acid transporters: structure, function, regulation and pathophysiological implications. Pharm Res. 2007;24:1803-1823.

12. Stieger B, Geier A. Genetic variations of bile salt transporters as predisposing factors for drug-induced cholestasis, intrahepatic cholestasis of pregnancy and therapeutic response of viral hepatitis. Expert Opin Drug Metab Toxicol. 2011; 7:411-425.

13. de Graaf W, Häusler S, Heger M, et al. Transporters involved in the hepatic uptake of ${ }^{99 \mathrm{~m}} \mathrm{Tc}-\mathrm{meb}$ rofenin and indocyanine green. J Hepatol. 2011;54: $738-745$.

14. van de Steeg E, Wagenaar E, van der Kruijssen CMM, et al. Organic anion transporting polypeptide $1 \mathrm{a} / 1 \mathrm{~b}$-knockout mice provide insights into hepatic handling of bilirubin, bile acids, and drugs. J Clin Invest. 2010;120:2942-2952.

15. Lengyel G, Veres Z, Tugyi R, et al. Modulation of sinusoidal and canalicular elimination of bilirubin-glucoronides by rifampicin and other cholestatic drugs in a sandwich culture of rat hepatocytes. Hepatol Res. 2008;38:300-309.

16. Kosters A, Karpen SJ. Bile acid transporters in health and disease. Xenobiotica. 2008;38:1043-1071.

17. Kullak-Ublick GA, Beuers U, Paumgartner G. Hepatobiliary transport. J Hepatol. 2000;32:3-18.

18. Vlaming ML, Mohrmann K, Wagenaar E, et al. Carcinogen and anticancer drug transport by Mrp2 in vivo: studies using Mrp2 (Abcc2) knockout mice. J Pharmacol Exp Ther. 2006;318:319-327.

19. Billinghurst MW, Eckert K, Mang'era K. Alternative quality control for technetium-99m IDA complexes. Appl Radiat Isot. 2004;61:1151-1155.

20. Vavricka SR, Van Montfoort J, Riem Ha H, Meier PJ, Fattinger K. Hepatology. 2002;36:164-172.

21. Mita S, Suzuki H, Akita H, et al. Inhibition of bile acid transport across $\mathrm{Na}+$ / taurocholate cotransporting polypeptide (SLC10A1) and bile salt export pump (ABCB 11)-coexpressing LLC-PK1 cells by cholestasis-inducing drugs. Drug Metab Dispos. 2006;34:1575-1581. 